\title{
Similar but Not the Same: First Kinetic and Structural Analyses of a Methanol Dehydrogenase Containing a Europium Ion in the Active Site
}

\author{
Bérénice Jahn, ${ }^{[a]}$ Arjan Pol, ${ }^{[b]}$ Henning Lumpe, ${ }^{[a]}$ Thomas R. M. Barends, ${ }^{[c]}$ Andreas Dietl, ${ }^{[c]}$ \\ Carmen Hogendoorn, ${ }^{[b]}$ Huub J. M. Op den Camp, ${ }^{[b]}$ and Lena J. Daumann*[a]
}

\begin{abstract}
Since the discovery of the biological relevance of rare earth elements (REEs) for numerous different bacteria, questions concerning the advantages of REEs in the active sites of methanol dehydrogenases (MDHs) over calcium(II) and of why bacteria prefer light REEs have been a subject of debate. Here we report the cultivation and purification of the strictly REE-dependent methanotrophic bacterium Methylacidiphilum fumariolicum SolV with europium(III), as well as structural and kinetic analyses of the first methanol dehydrogenase incorporating Eu in the active site. Crystal structure determination of the Eu$\mathrm{MDH}$ demonstrated that overall no major structural changes
\end{abstract}

were induced by conversion to this REE. Circular dichroism (CD) measurements were used to determine optimal conditions for kinetic assays, whereas inductively coupled plasma mass spectrometry (ICP-MS) showed $70 \%$ incorporation of Eu in the enzyme. Our studies explain why bacterial growth of SolV in the presence of $\mathrm{Eu}^{3+}$ is significantly slower than in the presence of $\mathrm{La}^{3+} / \mathrm{Ce}^{3+} / \mathrm{Pr}^{3+}$ : Eu-MDH possesses a decreased catalytic efficiency. Although REEs have similar properties, the differences in ionic radii and coordination numbers across the series significantly impact MDH efficiency.

\section{Introduction}

In April 2010, the blowout of the oil rig Deepwater Horizon caused an unprecedented release of natural gas and crude oil into the Gulf of Mexico. The plumes in the ocean led to a bloom of methanotrophic bacteria, and a recent study showed that, concurrently with methane consumption, a depletion of light rare earth elements (REEs: $\mathrm{La}, \mathrm{Ce}, \mathrm{Pr}$, and $\mathrm{Nd}$ ) from the surrounding seawater was observed. ${ }^{[1]}$ This phenomenon can be explained in terms of the biological role of REEs for methanotrophic and methylotrophic bacteria. ${ }^{[16,2]}$ These bacteria utilize $\mathrm{C} 1$ compounds, such as methane and methanol, as an

[a] B. Jahn, H. Lumpe, Prof. Dr. L. J. Daumann

Ludwig-Maximilians-Universität München, Department Chemie

Butenandtstr. 5-13, 81377 München (Germany)

E-mail:lena.daumann@cup.Imu.de

[b] Dr. A. Pol, C. Hogendoorn, Prof. Dr. H. J. M. Op den Camp Department of Microbiology

Institute of Wetland and Water Research, Radboud University Heyendaalseweg 135, 6525 AJ, Nijmegen (The Netherlands)

[c] Dr. T. R. M. Barends, A. Dietl

Department of Biomolecular Mechanisms

Max-Planck Institute for Medical Research

Jahnstrasse 29, 69120 Heidelberg (Germany)

$\square$ Supporting information and the ORCID identification numbers for the

(iD) authors of this article can be found under https://doi.org/10.1002/ cbic.201800130: growth experiments, CD-spectra, SDS-PAGE gel, geometryoptimized structures as well as the crystal structure and crystallographic data of Eu-MDH.

If (c) 2018 The Authors. Published by Wiley-VCH Verlag GmbH \& Co. KGaA This is an open access article under the terms of the Creative Commons Attribution-NonCommercial License, which permits use, distribution and reproduction in any medium, provided the original work is properly cited and is not used for commercial purposes. energy source. In the case of methanotrophs, methane is first oxidized by a methane monooxygenase, yielding methanol. Methanol, in turn, is metabolized through the action of quinoprotein methanol dehydrogenases (MDHs), REE- or calcium-dependent metalloenzymes that are widespread in nature. ${ }^{[3]}$ The first MDH to be isolated was from Methylobacterium extorquens

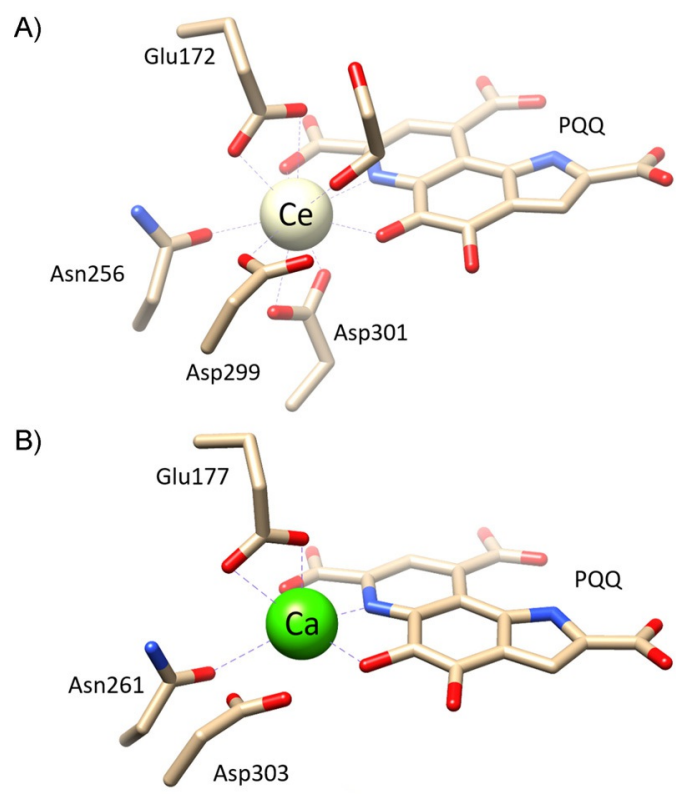

Figure 1. Active sites of $A$ ) the Ce-MDH from SolV strain (PDB ID: 4MAE) ${ }^{[9]}$ and $B$ ) the Ca-MDH from the strain M. extorquens (PDB ID: 1W6S). ${ }^{[5]}$ Images generated with the UCSF Chimera package. ${ }^{[10]}$ 
in 1964. ${ }^{[4]}$ This well-studied representative of the MxaF-type of oxidoreductases is found in the periplasm of bacteria and contains a calcium ion, in addition to the prosthetic group pyrroloquinoline quinone (PQQ) in the active site (Figure 1). ${ }^{[5]}$ In 2011, however, the induction of $\mathrm{MDH}$ by $\mathrm{La}^{3+}$ was mentioned in the literature, ${ }^{[6]}$ and one year later a catalytic role of $\mathrm{La}^{3+}$ was proposed for MDHs. ${ }^{[7]}$ In 2014 the first crystal structure of a REE-dependent MDH (XoxF-type) was published by Pol et al. (Figure 1). ${ }^{[2 b, 8]}$

The XoxF-type MDH from the extremophile Methylacidiphilum fumariolicum SolV, isolated after cultivation of SolV with mudpot water from its original habitat, the Solfatara crater near Naples, contains a REE in its active site. The crystal structure was refined with the most abundant REE found in this medium: cerium. ${ }^{[9]}$ Remarkably, the active sites of the REE$\mathrm{MDH}$ and $\mathrm{Ca}-\mathrm{MDH}$ s are highly conserved, with one exception. The REE-MDH contains an additional amino acid ligand, Asp301, presumably to satisfy the higher coordination number preferences of the trivalent REE, relative to divalent calcium (Figure 1). ${ }^{[\mathrm{bb}, 11]}$ Studies on methanotrophic and methylotrophic bacteria show that they carry either the mxaF or the xoxF gene or both, and can switch between them depending on their environment. ${ }^{[12]}$ In contrast to $M$. extorquens, which will preferentially express XoxF REE-MDH over MxaF Ca-MDH even when REEs are present at only nanomolar concentrations, strain SolV is strictly dependent on REEs and will not grow in the absence of these elements. ${ }^{[2 b, 8 f, 9]}$

It has been suggested that REE-dependent methanol dehydrogenases have catalytic activities superior to those of the calcium-dependent enzymes. REEs are stronger Lewis acids than calcium, a property proposed to be beneficial for PQQ cofactor activation. It should be noted, however, that the additional positive charge of the REE is partially compensated by the additional, negatively charged, Asp301 residue. Recent calculations by Schelter and co-workers suggested that the REE ion is especially advantageous in the redox cycling of $\mathrm{PQQ} .{ }^{[13]}$ From the few available kinetic studies for XoxF-type REE-MDH isolated from SolV, it is apparent that distinct catalytic differences from the MxaF-type Ca-MDH isolated from M. extorquens are observed in in vitro assays. ${ }^{[4,9]}$ The REE-MDH from SolV operates at a neutral $\mathrm{pH}$ optimum, whereas the $\mathrm{Ca}-\mathrm{MDH}$ displays its highest activity around $\mathrm{pH} 9$ and requires ammonia as an activator when the enzyme is assayed by using an artificial electron acceptor. ${ }^{[4,9,14]}$ Both MDH types are known also to oxidize higher carbon substrates, such as ethanol, and are capable of converting the oxidation product formaldehyde into formic acid. ${ }^{[3]}$

The mechanism of methanol oxidation by $\mathrm{Ca}-\mathrm{MDH}$ has been studied extensively for the past 40 years yet remains the subject of debate. A mechanism via a covalent hemiketal intermediate or a hydride transfer from methanol to the C 5 carbon of PQQ is considered possible. ${ }^{[4,15]}$ Recent work by Schelter on the first functional model of a REE-MDH implied this hydridetransfer mechanism. ${ }^{[1 \mathrm{~d}]}$

The discovery of the REE-MDH offers the opportunity to study MDH biochemistry from the point of view of the metal ion, because REEs offer multiple possibilities for spectroscopic investigation. ${ }^{[11]}$ In addition, higher substrate homologues, such as the ethanol dehydrogenase from $M$. extorquens, have recently been reported, ${ }^{[8 b]}$ and non-methylotrophic bacteria, such as Pseudomonas putida, have been found to express REEdependent alcohol dehydrogenases, thus demonstrating that REE dependency is limited neither to C1 substrates nor to methanotrophic or methylotrophic organisms. ${ }^{[8]}$ In addition to the fact that REEs are now known to be involved in the metabolism of methanotrophic bacteria, which are key players in the global methane greenhouse gas cycle, the need for new environmentally friendly approaches for the separation ${ }^{[16]}$ and recycling of these technologically indispensable elements puts research into REE-dependent bacteria in the spotlight. ${ }^{[8 \mathrm{a}, \mathrm{h}]}$ Here we report the purification and characterization of the first europium derivative of a methanol dehydrogenase from the strictly REE-dependent bacterial strain SoIV.

\section{Results and Discussion}

Cultivation of SolV with europium(III) and purification of the Eu-MDH was achieved by use of a protocol similar to a published procedure, although with $2 \mu \mathrm{M} \mathrm{EuCl} \cdot 6 \mathrm{H}_{2} \mathrm{O}$ in the growth medium instead of mudpot water. ${ }^{[9]}$ SolV exhibited exponential growth under these conditions. However, the growth rate (Figure S1 in the Supporting Information) was less than half $\left(0.032 \mathrm{~h}^{-1}\right)$ of those observed with the earlier, slightly larger rare earth elements (e.g., La, $\approx 0.085 \mathrm{~h}^{-1}$ ). This could be explained by the slightly smaller ionic radius (as a result of the lanthanide contraction) of europium(III) relative to lanthanum(III) or cerium(III). Uptake and intracellular metal ion transport mechanisms might have been evolutionarily tuned to the larger and more abundant REEs. Changes in the catalytic efficiency or methanol affinity of the REE-dependent enzyme $\mathrm{MDH}$ itself or impaired active site assembly in vivo are possible explanations. Like the mixed REE-MDH previously isolated from mudpot-water-cultivated SolV and La-MDH from M. extorquens, the purified Eu-MDH showed a band at $63.6 \mathrm{kDa}$ on a SDSPAGE gel (Figure S9). ${ }^{[6,9,17]}$ To determine the europium content of the purified $\mathrm{MDH}$, the fraction used for subsequent kinetic analysis was analyzed by inductively coupled plasma mass spectrometry (ICP-MS) and found to contain around $70 \%$ europium per $\mathrm{MDH}$ monomer, consistent with previous reports of REE content in the MDH purified from the SolV strain. ${ }^{[9]}$ The data suggest that the final assembly of a catalytically competent active site in vivo is not significantly influenced by the nature of the REE; however, metal uptake and intracellular transport, as well as the activity of the $\mathrm{MDH}$, might be affected.

Eu-MDH crystals diffracted to $1.4 \AA$ resolution, displayed triclinic symmetry, and contained four Eu-MDH molecules in the asymmetry unit. Of these, one (D) was poorly defined, as evidenced by large translation, libration and screw (TLS) parameters and poor electron density. That molecule was therefore not included in the following analysis. No large-scale differences between the previously published Ce-MDH and Eu-MDH structures were observed (Figures 2 and S7, Tables S1 and S2). 


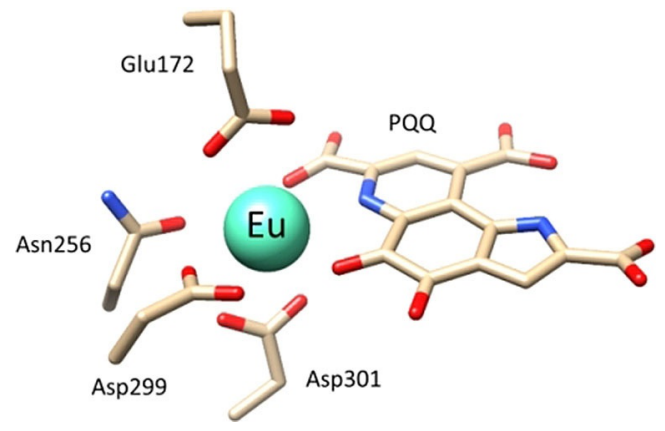

Figure 2. Close-up of the active site of the Eu-MDH (PDB ID: 6FKW) from SolV strain. Image generated with the UCSF Chimera package. ${ }^{[10]}$ Carbon atoms in beige, oxygen in red, nitrogen in blue, the europium ion in teal.

Difference electron density was observed at the location where the substrate is found in the REE-MDH (Figure 1), but this could not be explained in terms of a molecule of methanol, or any of the other buffer components, because this electron density disappeared upon refinement when any molecule was included in that position. We therefore refined this structure without substrate. Moreover, on comparison of the coordination distances in the Eu-MDH with those observed in the previously studied REE-MDHs, only very small differences are observed (Table S2); these are within the error margins of the experiments, even at this resolution. Thus, any differences in catalytic properties between the Eu-MDH and the other REE$\mathrm{MDH}$ s are not due to major rearrangements of PQQ or of the amino acid ligands in the active site.

The UV/Vis absorption spectrum of the Eu-MDH showed the characteristic features of the redox cofactor PQQ (Figure 3). As observed previously with the $\mathrm{MDH}$ isolated from the SolV

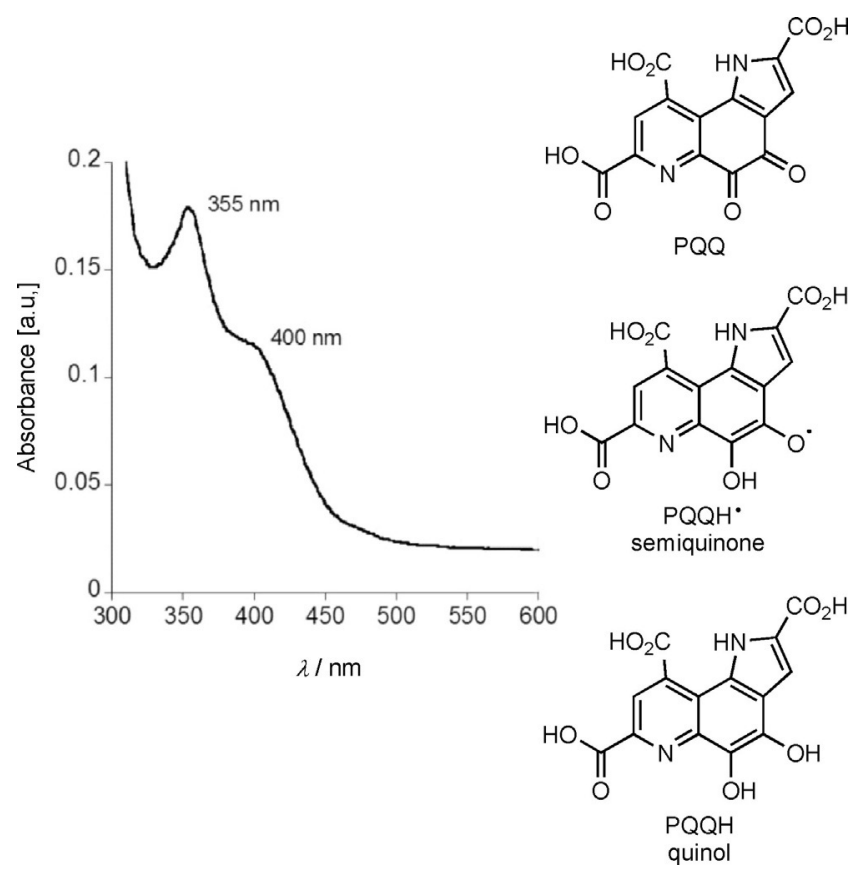

Figure 3. UV/Vis spectrum with the characteristic absorption of the cofactor $\mathrm{PQQ}$ in the purified Eu-MDH. Structures of different PQQ forms encountered in $\mathrm{MDH}$. strain, the maximum is found at $355 \mathrm{~nm}$, with a shoulder at $400 \mathrm{~nm}$. This suggests that no significant change in the absorption spectrum of $\mathrm{PQQ}$ is induced by changing the rare earth element from a mixture of mainly $\mathrm{Ce}^{3+}, \mathrm{La}^{3+}$, and $\mathrm{Pr}^{3+}$ to the smaller $\mathrm{Eu}^{3+}$. Anthony et al. analyzed $\mathrm{MxaF}-\mathrm{MDH}$ in the presence of both $\mathrm{Ca}^{2+}$ and $\mathrm{Ba}^{2+}$ and found no difference in the absorbance maximum upon substitution with those two metal ions in the active site of the MDH from M. extorquens. ${ }^{[18]}$ However, Harris and Davidson reported that the extinction coefficient of PQQ in the purified $\mathrm{MDH}$ was altered when $\mathrm{Ca}^{2+}$ was replaced by $\mathrm{Sr}^{2+}$ in the purification medium of Paracoccus denitrificans, although this observation can also be explained in terms of contamination with other proteins because the total ratio of the peaks at 280 and $345 \mathrm{~nm}$ was used for this interpretation ${ }^{[19]}$ A peak maximum at $355 \mathrm{~nm}$ seems to be typical for the $\mathrm{MDH}$ of the XoxF-type isolated from M. fumariolicum SolV, whereas the UV/Vis spectrum of the related Ca-MDH from M. extorquens shows this peak at $345 \mathrm{~nm}$. For the Ca$\mathrm{MDH}$ this absorption feature was attributed to the resting state of the enzyme, in which the cofactor was proposed to be in the semiquinone or the quinol form (Figure 3). ${ }^{[4,20]}$ The oxidized form of PQQ (with maxima in Ca-MDH reported around $400 \mathrm{~nm}$ ) is quickly turned over into one of the reduced forms by traces of methanol or endogenous substrate. ${ }^{[4]}$

Notably, in DFT calculations with $\mathrm{Eu}^{3+}$ or $\mathrm{Yb}^{3+}$ in the active site, Asp301 became a monodentate ligand (Figures S2 and S4) when substrate was included in the calculations, but this residue is bidentate in the crystal structure, in which no significant substrate density was present. It is known that the coordination number decreases within the REE series and this could provide one explanation for the differences observed during the growth of SolV. ${ }^{[16,9,11 a, 21]}$ The MDH active site might display lower affinity for substrate as the size of the REE decreases. Schelter and co-workers demonstrated that with $\mathrm{Ce}^{3+}$ in the active site (this REE is known also to exist in a tetravalent ceric state) the metal is not redox-active. ${ }^{[13]}$ It is very likely that europium, which can also adopt two different oxidation states (+ II and + III), is also not redox-active here. ${ }^{[11 a, 22]}$ However, to rule out experimentally the possibility of a redox-active Eu ion at any stage of the catalytic cycle, future studies will include ${ }^{151} \mathrm{Eu}$ Mössbauer spectroscopy or europium luminescence.

Circular dichroism spectra were recorded to study the stability and structure of the Eu-MDH in solution. The spectra in potassium phosphate (KP) buffer did not change over the $\mathrm{pH}$ range of 6 to 8 (Figure S5). A pH of 7.2, previously also shown to be the $\mathrm{pH}$ optimum for $\mathrm{Ce}-\mathrm{MDH}_{,}{ }^{[9]}$ was chosen for the kinetic assays. Strain SolV is an extremophile, living in high-temperature conditions $\left(50-60^{\circ} \mathrm{C}\right)$. However, $C D$ measurements showed that the purified $\mathrm{MDH}$ denatured under these conditions; hence a temperature of $45^{\circ} \mathrm{C}$ was chosen as a compromise between enzyme stability and activity. Furthermore, considering the small subunit Mxal present in $\mathrm{Ca}-\mathrm{MDH}$, which is lacking in REE-MDH, the spectra for Eu-MDH are in good agreement with the calculated spectra of Ca- and REE-MDH (Figure S6). ${ }^{[18,23]}$

Eu-MDH titration experiments were conducted to determine the additional amount of $\mathrm{Eu}^{3+}$ that is necessary to achieve full 
occupancy of all active sites. Although there is debate about whether this approach can be used to determine association constants, it is well-suited for comparison of the affinities of similar metals (i.e., REEs) or for determination of saturation for further kinetics investigations. ${ }^{[8,24]}$ Different concentrations of $\mathrm{EuCl}_{3}$ were added to the "partial-apo" Eu-MDH $(\approx 70 \%$ of active sites occupied by Eu). Results are presented in Figure S8 and demonstrate that enzymatic activity follows typical Michaelis-Menten behavior. The metal association constant was determined to be $(2.6 \pm 0.6) \mu \mathrm{m}$. We were also interested in how different REEs influence the activity of the $\mathrm{MDH}$, because they were shown to impact growth rates of strain SolV. Klebensberger and co-workers have shown that the specific activities of a PQQ-dependent ethanol dehydrogenase were dependent on the REE in question, with $\mathrm{Pr}^{3+}$ yielding a specific activity more than twice as high as that of the $\mathrm{La}^{3+}$ derivative. ${ }^{[8 \mathrm{~g}]}$ Our findings shown in Figure 4 support this observation and might provide an explanation for why strain SolV grows more slowly in the presence of $\mathrm{Eu}^{3+}$.

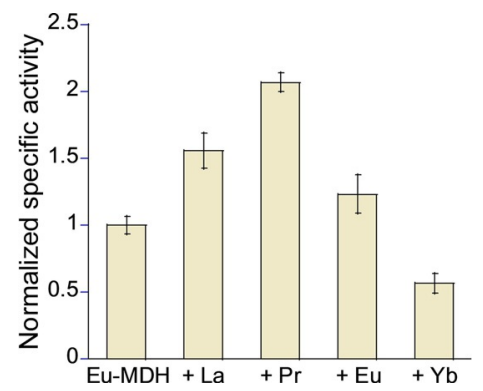

Figure 4. Titration of different REEs $(20 \mu \mathrm{M})$ against the Eu-MDH $(200 \mathrm{~nm})$. Conditions: $20 \mathrm{~mm}$ PIPES pH 7.2, $1 \mathrm{~mm}$ PES, $1 \mathrm{~mm} \mathrm{KCN}, 100 \mu \mathrm{m}$ DCPIP, $45^{\circ} \mathrm{C}$. Normalized specific enzymatic activity with standard error of the mean (SEM, $n=4)$ is shown.

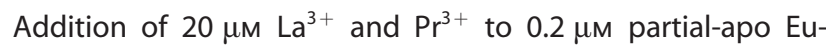
$\mathrm{MDH}$ increased the specific activity by factors of 1.5 and 2, respectively. As already shown in Eu titration experiments (Figure S8), the $\mathrm{MDH}$ activity also increases with the addition of $\mathrm{Eu}^{3+}$, albeit not as dramatically as with $\mathrm{La}^{3+}$ and $\mathrm{Pr}^{3+}$. The observed low activity in the presence of $\mathrm{Yb}^{3+}$ is surprising and might suggest that there is a dynamic exchange with the metal ion already bound to the active site (here Eu), because binding of $\mathrm{Yb}^{3+}$ in $30 \%$ of the apo-enzyme should lead either to no (additional) activity or to a catalytically competent active site. Future investigation into this matter could exploit the luminescent properties of $\mathrm{Eu}^{3+}$. $^{[25]}$

The decrease in activity of the Eu-MDH in the presence of $\mathrm{Yb}^{3+}$ prompted us to study the growth of strain SolV in the presence of this REE. One might assume that at a certain size growth can no longer be supported. Figure S1 demonstrates that, indeed, no exponential growth is observed in the presence of $\mathrm{Yb}^{3+}$, thus supporting a direct link of $\mathrm{MDH}$ activity to the growth rate. It is reasonable to assume that $\mathrm{Yb}^{3+}$ can bind to the active site, but that a catalytically competent active site is not formed with this REE. The absence of catalytic activity in the presence of $\mathrm{Yb}^{3+}$ was also observed by Klebensberger

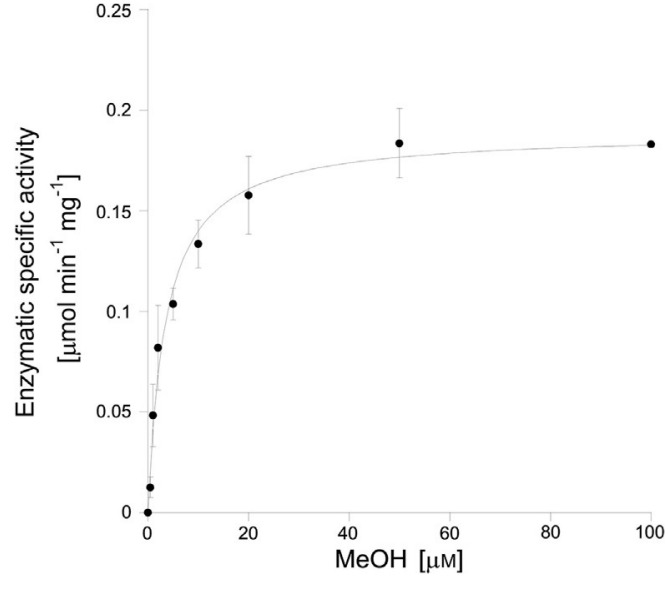

Figure 5. Specific enzymatic activity of $100 \mathrm{~nm}$ Eu-MDH supplemented with $20 \mu \mathrm{M} \mathrm{EuCl}{ }_{3}$ with SEM $(n=3)$. Conditions: $20 \mathrm{~mm}$ PIPES pH 7.2, $1 \mathrm{~mm}$ PES and KCN, $80 \mu \mathrm{M}$ DCPIP, $45^{\circ} \mathrm{C}$.

et al. with a REE-dependent alcohol dehydrogenase (PedH) isolated from P. putida KT2440. ${ }^{[8 \mathrm{gg}}$ Further, Masuda et al. recently reported that heavy REEs, such as $\mathrm{Ho}^{3+}$ and $\mathrm{Lu}^{3+}$, did not support growth of Methylobacterium aquaticum. ${ }^{[8]}$ Figure 5 shows the Michaelis-Menten kinetics of $100 \mathrm{~nm}$ Eu-MDH. The maximum turnover rate from the best curve fit was $(189 \pm 6) \mathrm{nmol}$ $\mathrm{min}^{-1} \mathrm{mg}^{-1}$. The corresponding Michaelis-Menten constant $K_{\mathrm{M}}$ was determined to be $(3.62 \pm 0.44) \mu \mathrm{m}$. Additionally, $k_{\text {cat }}$ was determined to be $0.20 \mathrm{~s}^{-1}$ and the catalytic efficiency $\left(k_{\mathrm{cat}} / K_{\mathrm{M}}\right)$ was $55.24 \mathrm{~mm}^{-1} \mathrm{~s}^{-1}$.

Remarkably, the affinity of the Eu-MDH in our experiments, with an affinity constant $\left(K_{\mathrm{M}}\right)$ of $(3.62 \pm 0.44) \mu \mathrm{M}$, was 4.5 times lower than that of the mixed REE-MDH ( $\mathrm{La}, \mathrm{Ce}, \mathrm{Pr}$ ) from strain SolV reported in the literature (obtained under slightly different assay conditions), with a $K_{\mathrm{M}}$ of $0.80 \mu \mathrm{m} .{ }^{[9]}$ Furthermore, the catalytic efficiency with $\mathrm{Eu}^{3+}$ instead of the earlier REEs was decreased more than 200 -fold. This could provide a plausible explanation for the slow growth of the strain SolV in the presence of that metal ion. However, to confirm this, La-MDH and the other derivatives would have to be isolated and purified from SolV (and other bacteria) and their kinetic parameters would have to be determined under the same conditions as used here, because the assay conditions are known to have a significant impact on these parameters. ${ }^{[9,26]}$ We are interested in whether or not these differences in activity are a direct result of the lanthanide contraction and concomitant change in coordination number or whether Lewis acidities and changes in PQQ activation must also be considered. The last two factors might provide an explanation for the differences in activity of La- or Pr-dependent MDH compared to Eu-MDH (Figure 4).

\section{Conclusion}

The coordination chemistry of REEs is known to show a high degree of structural diversity, and the absence of strong ligand field effects can make predictions of the coordination numbers and geometry difficult. ${ }^{[27]}$ In REE dependent methanol dehydro- 
genases almost all ligands and the coordination geometry are determined by the protein environment and result in a coordination number of nine. Addition of the substrate as a tenth ligand might depend on the nature and characteristics of the REE ion in the active site. As Cotton and Raithby so appropriately describe it: "discontinuities can arise at any point in the lanthanide series, so where possible each of the elements should be examined in any particular study."[28] To conclude, we present the first structural and kinetic study of a methanol dehydrogenase with a europium ion in the active site and isolated from a strictly REE-dependent bacterium. Our results show that, although rare earth elements have similar properties, the differences in ionic radii and coordination numbers across the series impact the catalytic efficiency of this $\mathrm{MDH}$, which might explain why bacteria depend on the larger, more abundant REEs for growth.

\section{Experimental Section}

Strain, medium, and culture conditions: The cultivation of strain SolV with europium was carried out by using a slightly modified previously described protocol. ${ }^{[9,29]}$ The growth medium contained $\mathrm{MgCl}_{2} \cdot 6 \mathrm{H}_{2} \mathrm{O}(0.2 \mathrm{~mm}), \mathrm{Na}_{2} \mathrm{SO}_{4}(1 \mathrm{~mm}), \mathrm{K}_{2} \mathrm{SO}_{4}(2 \mathrm{~mm}),\left(\mathrm{NH}_{4}\right)_{2} \mathrm{SO}_{4}$ (4 mM), $\mathrm{NaH}_{2} \mathrm{PO}_{4} \cdot \mathrm{H}_{2} \mathrm{O}(1 \mathrm{~mm})$, and $\mathrm{CaCl}_{2} \cdot 2 \mathrm{H}_{2} \mathrm{O}(0.2 \mathrm{~mm})$, as well as the trace elements $\mathrm{FeSO}_{4} \cdot 7 \mathrm{H}_{2} \mathrm{O}(2 \mu \mathrm{M}), \mathrm{ZnSO}_{4} \cdot 7 \mathrm{H}_{2} \mathrm{O}(0.1 \mu \mathrm{M})$, $\mathrm{CoCl}_{2} \cdot 6 \mathrm{H}_{2} \mathrm{O}(0.1 \mu \mathrm{M}), \mathrm{MnCl}_{2} \cdot 4 \mathrm{H}_{2} \mathrm{O}(2 \mu \mathrm{M}), \mathrm{CuSO}_{4} \cdot 5 \mathrm{H}_{2} \mathrm{O} \quad(3 \mu \mathrm{M})$, $\mathrm{NiCl}_{2} \cdot 6 \mathrm{H}_{2} \mathrm{O}(0.1 \mu \mathrm{M}), \quad \mathrm{Na}_{2} \mathrm{MoO}_{4} \cdot 2 \mathrm{H}_{2} \mathrm{O}(0.1 \mu \mathrm{M})$, and $\mathrm{EuCl}_{3} \cdot 6 \mathrm{H}_{2} \mathrm{O}$ $(2 \mu \mathrm{M})$. Large-scale cultivation was performed in a $10 \mathrm{~L}$ fermenter (Applikon, Schiedam, the Netherlands). The liquid volume was $5 \mathrm{~L}$, the $\mathrm{pH}$ was adjusted to 2.8 , and the temperature was set to $55^{\circ} \mathrm{C}$ Methane $\left(8-100 \mathrm{~mL} \mathrm{~min}^{-1}\right)$ was supplied to the reactor. The air supply was $50-1200 \mathrm{~mL} \mathrm{~min}^{-1}$ and the agitation speed was between 400 and $1000 \mathrm{rpm}$, in order to maintain a dissolved oxygen concentration of up to $10 \%$ air saturation.

Yb batch cultivation: In this study the medium was composed of $\mathrm{MgCl}_{2} \cdot 6 \mathrm{H}_{2} \mathrm{O}(0.2 \mathrm{~mm}), \mathrm{Na}_{2} \mathrm{SO}_{4}(1 \mathrm{~mm}), \mathrm{K}_{2} \mathrm{SO}_{4}(2 \mathrm{~mm}),\left(\mathrm{NH}_{4}\right)_{2} \mathrm{SO}_{4}$ $(2 \mathrm{~mm}), \mathrm{NaH}_{2} \mathrm{PO}_{4} \cdot \mathrm{H}_{2} \mathrm{O}(1 \mathrm{~mm})$, and $\mathrm{CaCl}_{2} \cdot 2 \mathrm{H}_{2} \mathrm{O}(0.2 \mathrm{~mm})$, as well as the trace elements $\mathrm{FeSO}_{4} \cdot 7 \mathrm{H}_{2} \mathrm{O}(2 \mu \mathrm{M}), \mathrm{ZnSO}_{4} \cdot 7 \mathrm{H}_{2} \mathrm{O}(0.1 \mu \mathrm{M})$, $\mathrm{CoCl}_{2} \cdot 6 \mathrm{H}_{2} \mathrm{O}(0.1 \mu \mathrm{M}), \quad \mathrm{MnCl}_{2} \cdot 4 \mathrm{H}_{2} \mathrm{O}(2 \mu \mathrm{M}), \mathrm{CuSO}_{4} \cdot 5 \mathrm{H}_{2} \mathrm{O} \quad(3 \mu \mathrm{M})$, $\mathrm{NiCl} \cdot 6 \mathrm{H}_{2} \mathrm{O}(0.1 \mu \mathrm{M}), \mathrm{Na}_{2} \mathrm{MoO}_{4} \cdot 2 \mathrm{H}_{2} \mathrm{O}(0.1 \mu \mathrm{M})$, and $\mathrm{Yb}\left(\mathrm{NO}_{3}\right)_{3} \cdot 5 \mathrm{H}_{2} \mathrm{O}$ $(1 \mu \mathrm{M})$. The stock solution of the trace elements was dissolved in sulfuric acid $(1-2 \%, v / v)$ before addition to the bulk medium solution. The $\mathrm{pH}$ of the medium was adjusted to 2.7 with $\mathrm{H}_{2} \mathrm{SO}_{4}(1 \mathrm{M})$. Cells were grown in a $500 \mathrm{~mL}$ serum bottle containing medium $(100 \mathrm{~mL})$ and sealed with red butyl rubber stoppers. The headspace contained air together with $\mathrm{CH}_{4}(10 \mathrm{v} \%)$ and $\mathrm{CO}_{2}(5 \mathrm{v} \%)$. The cultures were incubated at $55^{\circ} \mathrm{C}$ with shaking at $200 \mathrm{rpm}$. Incubations were performed in duplicate. Approximately every $12 \mathrm{~h}$, samples were taken for $\mathrm{OD}_{600}$ measurements with a Cary 50 UV/Vis spectrophotometer.

Purification of Eu-MDH was carried out according to a previously published protocol reported by Pol et al..$^{[9]}$ Cells were harvested at an $\mathrm{OD}_{600}$ of 7.5 and were broken with a French press at 20000 psi. Cell debris and membranes were removed by centrifugation, and cell-free extract protein was applied to an ice-cooled SP-Sepharose-FF (GE Healthcare) cation-exchange column $(1.6 \times 20 \mathrm{~cm})$ that had been equilibrated with PIPES buffer $(20 \mathrm{~mm}, \mathrm{pH} 7.2)$ containing methanol $(1 \mathrm{~mm})$. The addition of methanol was essential to ensure long-term stability and activity of the Eu-MDH. The enzyme was eluted by using a linear gradient of $\mathrm{NaCl}(0-500 \mathrm{~mm})$ in PIPES buffer. (PIPES buffer was used instead of phosphate buffer to avoid precipitation of $\mathrm{EuPO}_{4}$ during purification and storage.)

Determination of protein concentration by the Edelhoch method: ${ }^{[30]}$ Protein concentration was measured spectrophotometrically with a Cary 60 UV/Vis spectrophotometer. The absorption of the purified Eu-MDH at $280 \mathrm{~nm}$ was utilized for calculating protein concentration by application of the Lambert-Beer Law with use of an extinction coefficient $(\varepsilon)$ for the $\mathrm{MDH}$ monomer of $158 \mathrm{~cm}^{-1} \mathrm{~mm}^{-1}$.

ICP-MS: The europium content was determined with a Series I ICPMS (Thermo Scientific, Breda, the Netherlands). A fraction containing the MDH $(31.0 \mu \mathrm{M})$ was digested with nitric acid. A total of four samples were analyzed for Eu and yielded an average Eu content of $(22.2 \pm 1.1) \mu \mathrm{M}$. Thus, Eu occupancy in purified Eu-MDH was $71.7 \%$.

Washing procedure: A washing procedure, to remove degraded protein and residual methanol, formaldehyde, and formate from the enzyme prior to kinetic experiments, was used. Each protein sample was diluted in chelexed PIPES buffer $(20 \mathrm{~mm}, \mathrm{pH} 7.2)$ in a 1:10 ratio before centrifugation. PIPES was treated with Chelex 100 (sodium salt, Sigma-Aldrich, 50-100 mesh) for at least one hour prior to use to remove any metal ions that might interfere with kinetic experiments. Chelex 100 was removed from the buffer with a syringe filter $(0.45 \mu \mathrm{m}$, nylon membrane, VWR). The diluted protein was centrifuged at $4500 \mathrm{rpm}$ (Heraeus Megafuge $8 \mathrm{R}$ with TX150 rotor, radius: $144 \mathrm{~mm}$ ) and $4{ }^{\circ} \mathrm{C}$ until the initial volume was reached by using a centrifugal filter unit with a $30 \mathrm{kDa}$ molecular weight cut-off (Vivaspin 6, Sartorius, Germany). The washed enzyme had to be used on the same day for analysis, because stability in the absence of methanol was poor. The washing did not affect protein integrity, as was shown by SDS-PAGE (Figure S9).

UV/Vis spectroscopy: Spectra and kinetics data were acquired on an Agilent Cary 60 UV/Vis spectrophotometer with a Peltier Element and water pump. To avoid photodegradation of phenazine ethosulfate while performing kinetic experiments, the lid of the spectrometer was kept closed during the measurements and the reagent was stored in an amber vial. The sample cuvette holder was left to equilibrate to the set temperature $\left(45^{\circ} \mathrm{C}\right)$ for at least one hour prior to the measurements.

Circular dichroism (CD) spectra were recorded with a JASCO J$810 \mathrm{CD}$ and $\mathrm{ORD}$ spectropolarimeter at $25^{\circ} \mathrm{C}$. A scanning speed of $20 \mathrm{~nm} \mathrm{~min}^{-1}$, a data pitch of $0.1 \mathrm{~nm}$, a data integration time of $1 \mathrm{~s}$, and a bandwidth of $1 \mathrm{~nm}$ were used. A baseline spectrum of the buffer was recorded and subtracted from the protein spectrum. The spectra (Figure S5) represent averages of five measurements and were recorded $5 \mathrm{~min}$ after mixing and at $25^{\circ} \mathrm{C}$. CD data below $210 \mathrm{~nm}$ were not included, because of the strong absorption of the buffers below $210 \mathrm{~nm}$. The spectra were normalized to an ellipticity of -1 in the $210-230 \mathrm{~nm}$ region. The software used for data acquisition and analysis was Spectra Manager version 2.06.00. Calculations of the CD spectra were performed by using DichroCalc http://comp.chem.nottingham.ac.uk/dichrocalc/. ${ }^{[31]}$ The PDB codes $4 \mathrm{MAE}$ and $1 \mathrm{~W} 6 \mathrm{~S}$ were used as inputs for REE-MDH and $\mathrm{Ca}-\mathrm{MDH}$, respectively.

SDS-PAGE was performed with a BioRad electrophoresis chamber. Samples were denatured for $1 \mathrm{~min}$ at $95^{\circ} \mathrm{C}$, and $2 \mu \mathrm{g}$ of protein were loaded per lane onto the gel. BLUeye prestained protein ladder ( $\mathrm{M}$, Sigma-Aldrich) was used as marker. MDH was analyzed on a $10 \%$ SDS acrylamide gel that was run at $100 \mathrm{~V}$ and $500 \mathrm{~mA}$ 
for $20 \mathrm{~min}$ and subsequently at $200 \mathrm{~V}$ and $500 \mathrm{~mA}$ for $1 \mathrm{~h}$. Bands were visualized with Coomassie Brilliant Blue stain (Figure S9).

Dye-coupled assay: A dye-coupled assay was used for enzymatic activity determination. Substrate conversion was visualized by the reduction of the redox-active dye 2,6-dichlorophenolindophenol (DCPIP, the sodium salt hydrate, Sigma-Aldrich, $90 \%$ purity). For coupling substrate consumption to DCPIP, the artificial electronacceptor phenazine ethosulfate (PES, Sigma-Aldrich, 95\% purity) was used. Chelexed 2,2'-(piperazine-1,4-diyl)diethanesulfonic acid (PIPES, Sigma-Aldrich, $99 \%$ purity) was used as buffer.

Enzyme kinetics: A stock solution of the assay mixture was prepared by combining freshly prepared buffered (PIPES, pH 7.2, $20 \mathrm{~mm})$ solutions of PES $(100 \mathrm{~mm}), \mathrm{KCN}(100 \mathrm{~mm})$, and DCPIP (20 mM) and was incubated for $15 \mathrm{~min}$ at $45^{\circ} \mathrm{C}$ in the dark. The incubation period was necessary to alleviate background reactions of the assay mix in the absence of enzyme. Storage in the dark was absolutely necessary to avoid photodegradation and radical formation by the electron acceptor PES. ${ }^{[32]}$ For metal titrations the final assay mixture contained PES (1 $\mathrm{mm}), \mathrm{KCN}(1 \mathrm{~mm})$, DCPIP $(80 \mu \mathrm{M})$, and $\mathrm{MeOH}(4 \mathrm{~mm})$; different concentrations of $\mathrm{EuCl}_{3}$ ranging from 0 to $50 \mu \mathrm{m}$ were added to the cuvette directly. Europiu$\mathrm{m}$ (III) addition beyond $50 \mu \mathrm{m}$ did not improve enzymatic activity, and higher concentrations led to an unwanted background reaction of the assay components in the absence of enzyme. In the case of Michaelis-Menten kinetics, Eu"I' (europium chloride hexahydrate purchased from Sigma-Aldrich, $99.99 \%$ trace metals basis, $20 \mu \mathrm{M}$ ) was included in the assay mix to ensure full substitution of the active site of the enzyme. Substrate concentrations were varied from $0-100 \mu \mathrm{M} \mathrm{MeOH}$. The final mixture for MichaelisMenten kinetics contained PES (1 mM), KCN (1 mM), DCPIP $(80 \mu \mathrm{m})$, and $\mathrm{Eu}^{\mathrm{III}}(20 \mu \mathrm{M})$ and was combined with the desired methanol (Fisher Scientific, HPLC grade) concentration in a cuvette (QS, Hellma Analytics, with magnetic stir bar and Teflon stopper). Measurements were performed by monitoring the background reaction for one $\min$ at $600 \mathrm{~nm}$ before the addition of the MDH (100 nM). In the case of metal titrations, methanol was added to the assay mix before $\mathrm{MDH}$ addition. For enzyme kinetics, methanol was added after residual methanol in the MDH sample had been used up by the enzyme. Additionally, excess methanol (2.5 M) was added after another three min to correct for fluctuations in activity during the day. Initial rates (the first $1.5 \mathrm{~min}$ of the slope) were used for the calculation of specific enzymatic activity. All experiments were monitored at a wavelength of $600 \mathrm{~nm}$ and conducted at $45^{\circ} \mathrm{C}$ in the dark with stirring. To calculate the specific activity, an extinction coefficient of $18.5 \mathrm{~cm}^{-1} \mathrm{~mm}^{-1}$ for DCPIP was used. DCPIP shows a strong $\mathrm{pH}$ dependence, so it is crucial to maintain an exact $\mathrm{pH}$ of 7.2 in the buffered assay solutions. ${ }^{[9,33]}$ Enzyme kinetics were fit by using the Michaelis-Menten Equation (1):

$v_{0}=\frac{v_{\max }[\mathrm{S}]}{K_{\mathrm{M}}+[\mathrm{S}]}$

with $v_{0}$ being the initial velocity, $v_{\max }$ the maximum turnover speed, [S] the substrate concentration, and $K_{\mathrm{M}}$ the MichaelisMenten constant. In the case of metal titrations $K_{\mathrm{M}}$ denotes $K_{\text {assoc }}$ the metal association constant.

Plate reader assay with different metal ions: The dye-coupled assay was adapted ${ }^{[8 g]}$ for this experiment with use of 96 -well microtiter plates and the Epoch2 plate reader from BioTek (Winooski, VT, USA). Each well contained assay mix [180 $\mu \mathrm{L}$, PIPES (pH 7.2, $20 \mathrm{~mm})$, DCPIP $(100 \mu \mathrm{m})$, PES $(1 \mathrm{~mm}), \mathrm{KCN}(1 \mathrm{~mm})]$, Eu-MDH $(200 \mathrm{~nm})$, and-variously- $\mathrm{LaCl}_{3}, \mathrm{PrCl}_{3}, \mathrm{EuCl}_{3}$, or $\mathrm{YbCl}_{3}(0.4 \mathrm{~mm}$,
$10 \mu \mathrm{L})$, or Millipore water $(10 \mu \mathrm{L})$. The assay mix was incubated for $5 \mathrm{~min}$ at $45^{\circ} \mathrm{C}$ before the $\mathrm{MDH}$ and metal ions were added. After $2 \mathrm{~min}$ the reaction was started with the addition of a $\mathrm{MeOH}$ solution $(1 \mathrm{M}, 10 \mu \mathrm{L})$, resulting in a total volume of $200 \mu \mathrm{L}$, and monitored at $600 \mathrm{~nm}$. On average four measurements were taken to calculate specific activities.

DFT calculations: Structure optimizations were performed with Gaussian $09^{[34]}$ and the B3LYP functional with the $6-31 \mathrm{G}(\mathrm{d})$ basis set for $\mathrm{C}, \mathrm{H}, \mathrm{N}, \mathrm{O} .^{[35]}$ Quasi-relativistic effective core potentials (ECPs) were used for the central metal: MWB46 for $\mathrm{La}^{3+},-47$ for $\mathrm{Ce}^{3+},-48$ for $\mathrm{Pr}^{3+},-52$ for $\mathrm{Eu}^{3+}$, and -59 for $\mathrm{Yb}^{3+}$ (Figures $\mathrm{S} 2-$ S4). ${ }^{\left[{ }^{[6]}\right.}$ Calculations were performed with 11 outer-sphere electrons, as pseudo-singlets (f-electrons included in ECP) and restricted closed-shell calculations. None of the frequency calculations showed negative values. The starting point of the geometry optimization was the active site of the crystal structure of the $\mathrm{Ce}-\mathrm{MDH}$ isolated from SolV (4MAE), with exchange of $\mathrm{Ce}^{3+}$ with $\mathrm{La}^{3+}, \mathrm{Pr}^{3+}$, $\mathrm{Yb}^{3+}$, and $\mathrm{Eu}^{3+}$. The amino acid residues and the polyethylene glycol present in the crystal structure were truncated by a method based on that of Schelter et al., and the anchoring carbon atoms were frozen in their crystallographic positions to mimic the sterics imposed by the protein. ${ }^{[13]}$ For simplification, only the cofactor $\mathrm{PQQ}$ and the amino acids directly coordinating to the metal ions were included in the calculations.

Crystal structure determination: Eu-MDH was concentrated by ultrafiltration to an $A_{280}$ of 7.52 in HEPES/KOH $(25 \mathrm{~mm}, \mathrm{pH} 7.5)$ containing $\mathrm{KCl}(25 \mathrm{~mm})$ and methanol $(1 \mathrm{~mm})$. Crystals were obtained by using the hanging drop vapor diffusion method, by mixing protein solution $(1.5 \mu \mathrm{L})$ with reservoir solution [1.5 $\mu \mathrm{L}$, PEG 8000 $(24 \%, w / v), \mathrm{NaCl}(0.3 \mathrm{M})]$ followed by equilibration against that solution. Crystals grew within a few days at $20^{\circ} \mathrm{C}$, were cryoprotected by soaking for $5 \mathrm{~min}$ in PEG $8000(25 \%), \mathrm{NaCl}(0.3 \mathrm{M})$, and ethylene glycol $(20 \%)$ and then flash-cooled in liquid nitrogen. Data were collected at the PXII beam line of the Swiss Light Source (Villigen, $\mathrm{CH})$. Initial phases were calculated by using the previously published REE-MDH structure (PDB ID: 4MAE). Refinement was carried out with REFMAC5 and use of TLS parameters and riding hydrogens for the protein and anisotropic B-factors for the Eu ions. ${ }^{[37]}$

The crystal structure and structure factors have been deposited in the Protein Databank under ID: 6FKW.

\section{Acknowledgements}

L.J.D. thanks Prof. Peter Klüfers for access to the $C D$ instrument and Simone Graf from BioTek for allowing a test of the Epoch2. T.R.M.B. would like to thank Ilme Schlichting for continuous support. L.J.D. is supported by the LMU and the SFB 749. C.H. and H.O.d.C. are supported by the European Research Council (ERC Advanced Grant project VOLCANO 669371).

\section{Conflict of Interest}

The authors declare no conflict of interest.

Keywords: europium . lanthanides . methanol
dehydrogenases $\cdot$ oxidoreductases $\cdot$ rare earths

[1] a) B. Graham, W. K. Reilly, F. Beinecke, D. F. Boesch, T. D. Garcia, C. A. Murray, F. Ulmer, Deep Water, The Gulf Oil Disaster and the Future of Off- 
shore Drilling. Report to the President, National Commission on the BP Deepwater Horizon Oil Spill and Offshore Drilling, 2011; b) A. M. Shiller E. W. Chan, D. J. Joung, M. C. Redmond, J. D. Kessler, Sci. Rep. 2017, 7, 1-9; c) J. D. Kessler, D. L. Valentine, M. C. Redmond, M. Du, E. W. Chan, S. D. Mendes, E. W. Quiroz, C. J. Villanueva, S. S. Shusta, L. M. Werra, S. A. Yvon-Lewis, T. C. Weber, Science 2011, 331, 312-315; d) A. McSkimming T. Cheisson, P. J. Carroll, E. J. Schelter, J. Am. Chem. Soc. 2018, 140, $1223-1226$.

[2] a) A. M. Ochsner, F. Sonntag, M. Buchhaupt, J. Schrader, J. A. Vorholt, Appl. Microbiol. Biotechnol. 2015, 99, 517-534; b) H. N. Vu, G. A. Subuyuj, S. Vijayakumar, N. M. Good, N. C. Martinez-Gomez, E. Skovran, J. Bacteriol. 2016, 198, 1250-1259.

[3] J. Keltjens, A. Pol, J. Reimann, H. M. J. Op den Camp, Appl. Microbiol. Biotechnol. 2014, 98, 6163-6183.

[4] C. Anthony in Subcellular Biochemistry Vol. 35 (Eds.: A. Holzenburg, N. S. Scrutton), 2000, pp. 73-117.

[5] P. A. Williams, L. Coates, F. Mohammed, R. Gill, P. T. Erskine, A. Coker, S. P. Wood, C. Anthony, J. B. Cooper, Acta Crystallogr. Sect. D Biol. Crystallogr. 2005, 61, 75-79.

[6] Y. Hibi, K. Asai, H. Arafuka, M. Hamajima, T. Iwama, K. Kawai, J. Biosci. Bioeng. 2011, 111, 547-549.

[7] T. Nakagawa, R. Mitsui, A. Tani, K. Sasa, S. Tashiro, T. Iwama, T. Hayakawa, K. Kawai, PLoS One 2012, 7, e50480.

[8] a) E. Skovran, N.C. Martinez-Gomez, Science 2015, 348, 862-863 b) N. M. Good, H. N. Vu, C. J. Suriano, G. A. Subuyuj, E. Skovran, N. C. Martinez-Gomez, J. Bacteriol. 2016, 198, 3109-3118; c) S. M. B. Krause, T. Johnson, Y. Samadhi Karunaratne, Y. Fu, D. A. C. Beck, L. Chistoserdova M. E. Lidstrom, Proc. Natl. Acad. Sci. USA 2017, 114, 358-363; d) D. A. C. Beck, T. L. McTaggart, U. Setboonsarng, A. Vorobev, M. G. Kalyuzhnaya, N. Ivanova, L. Goodwin, T. Woyke, M. E. Lidstrom, L. Chistoserdova, PLoS One 2014, 9, e102458; e) F. Chu, M. E. Lidstrom, J. Bacteriol. 2016, 198, 1317-1325; f) F. Chu, D. A. C. Beck, M. E. Lidstrom, PeerJ 2016, 4, e2435 g) M. Wehrmann, P. Billard, A. Martin-Meriadec, A. Zegeye, J. Klebensberger, mBio 2017, 8, e00570-17; h) L. Chistoserdova, World J. Microbiol. Biotechnol. 2016, 32, 138; i) M. Farhan UI Haque, B. Kalidass, N. Bandow E. A. Turpin, A. A. Dispirito, J. D. Semrau, Appl. Environ. Microbiol. 2015, 81, $7546-7552$; j) S. Masuda, Y. Suzuki, Y. Fujitani, R. Mitsui, T. Nakagawa, M. Shintani, A. Tani, mSphere 2018, 3, e00462-17.

[9] A. Pol, T. R. M. Barends, A. Dietl, A. F. Khadem, J. Eygensteyn, M. S. M. Jetten, H. J. M. Op den Camp, Environ. Microbiol. 2014, 16, 255-264.

[10] E. F. Pettersen, T. D. Goddard, C. C. Huang, G. S. Couch, D. M. Greenblatt, E. C. Meng, T. E. Ferrin, J. Comput. Chem. 2004, 25, 1605-1612.

[11] a) S. Cotton, Lanthanide and Actinide Chemistry, Wiley, Chichester, 2006; b) C. H. Evans, Biochemistry of the Lanthanides, Springer, New York, 1990.

[12] J. D. Semrau, A. A. DiSpirito, W. Gu, S. Yoon, Appl. Environ. Microbiol. 2018, 84, e02289-17.

[13] J. A. Bogart, A. J. Lewis, E. J. Schelter, Chem. Eur. J. 2015, 21, 1743-1748.

[14] P. R. Afolabi, F. Mohammed, K. Amaratunga, O. Majekodunmi, L. Dales, R. Gill, D. Thompson, B. Cooper, P. Wood, M. Goodwin, C. Anthony, Biochemistry 2001, 40, 9799-9809.

[15] a) M. Leopoldini, N. Russo, M. Toscano, Chem. Eur. J. 2007, 13, 21092117; b) S. Itoh, H. Kawakami, S. Fukuzumi, J. Am. Chem. Soc. 1997, 119, 439-440; c) S. Itoh, H. Kawakami, S. Fukuzumi, Biochemistry 1998, 37, $6562-6571$; d) S. Itoh, H. Kawakami, S. Fukuzumi, J. Mol. Catal. B 2000 8, 85-94; e) J. M. Cox, D. J. Day, C. Anthony, Biochim. Biophys. Acta Protein Struct. Mol. Enzymol. 1992, 1119, 97-106; f) C. Anthony, P. Williams, Biochim. Biophys. Acta Proteins Proteomics 2003, 1647, 18-23; g) M. Prejanò, T. Marino, N. Russo, Chem. Eur. J. 2017, 23, 8652-8657; h) A. J. J. Olsthoorn, J. A. Duine, Biochemistry 1998, 37, 13854-13861; i) A. Oubrie, H. J. Rozeboom, K. H. Kalk, A. J. Olsthoorn, J. A. Duine, B. W. Dijkstra, EMBO J. 1999, 18, 5187-5194.
[16] W. D. Bonificio, D. R. Clarke, Environ. Sci. Technol. Lett. 2016, 3, 180 - 184

[17] N. A. Fitriyanto, M. Fushimi, M. Matsunaga, A. Pertiwiningrum, T. Iwama, K. Kawai, J. Biosci. Bioeng. 2011, 111, 613-617.

[18] M. G. Goodwin, A. Avezoux, S. L. Dales, C. Anthony, Biochem. J. 1996, $319,839-842$.

[19] T. K. Harris, V. L. Davidson, Biochem. J. 1994, 300, 175-182.

[20] A. Jongejan, S. S. Machado, J. A. Jongejan, J. Mol. Catal. B 2000, 8, 121 163.

[21] S. A. Cotton, C. R. Chim. 2005, 8, 129-145.

[22] N. Kaltsoyannis, P. Scott, The f Elements, Oxford University Press, Oxford, 1999.

[23] M. Ghosh, C. Anthony, K. Harlos, M. G. Goodwin, C. Blake, Structure $1995,3,177-187$.

[24] a) L. J. Daumann, B. Y. McCarthy, K. S. Hadler, T. P. Murray, L. R. Gahan, J. A. Larrabee, D. L. Ollis, G. Schenk, Biochim. Biophys. Acta Proteins Proteomics 2013, 1834, 425-432; b) Z. Xiao, A. G. Wedd, Nat. Prod. Rep. 2010, 27, 768-789.

[25] N. Sule, R. K. Singh, P. Zhao, D. K. Srivastava, J. Inorg. Biochem. 2012, $106,84-89$

[26] P. Hothi, J. Basran, M. J. Sutcliffe, N. S. Scrutton, Biochemistry 2003, 42, 3966-3978.

[27] M. Seitz, A. G. Oliver, K. N. Raymond, J. Am. Chem. Soc. 2007, 129, $11153-11160$

[28] S. A. Cotton, P. R. Raithby, Coord. Chem. Rev. 2017, 340, 220-231.

[29] A. F. Khadem, M. C. F. van Teeseling, L. van Niftrik, M. S. M. Jetten, H. J. M. Op den Camp, A. Pol, Front. Microbiol. 2012, 3, 345.

[30] N. C. Pace, F. Vajdos, L. Fee, G. Grimsley, T. Gray, Protein Sci. 1995, 4 , $2411-2423$.

[31] B. M. Bulheller, J. D. Hirst, Bioinformatics 2009, 25, 539-540.

[32] R. Ghosh, J. R. Quayle, Anal. Biochem. 1979, 99, 112-117.

[33] J. M. Armstrong, Biochim. Biophys. Acta Gen. Subj. 1964, 86, 194-197.

[34] Gaussian 09, M. J. Frisch, G. W. Trucks, H. B. Schlegel, G. E. Scuseria, M. A. Robb, J. R. Cheeseman, G. Scalmani, V. Barone, B. Mennucci, G. A. Petersson, H. Nakatsuji, M. Caricato, X. Li, H. P. Hratchian, A. F. Izmaylov, J. Bloino, G. Zheng, J. L. Sonnenberg, M. Hada, M. Ehara, K. Toyota, R. Fukuda, J. Hasegawa, M. Ishida, T. Nakajima, Y. Honda, O. Kitao, H. Nakai, T. Vreven, J. A. Montgomery, Jr., J. E. Peralta, F. Ogliaro, M. J. Bearpark, J. Heyd, E. N. Brothers, K. N. Kudin, V. N. Staroverov, R. Kobayashi, J. Normand, K. Raghavachari, A. P. Rendell, J. C. Burant, S. S. lyengar, J. Tomasi, M. Cossi, N. Rega, N. J. Millam, M. Klene, J. E. Knox, J. B. Cross, V. Bakken, C. Adamo, J. Jaramillo, R. Gomperts, R. E. Stratmann, O. Yazyev, A. J. Austin, R. Cammi, C. Pomelli, J. W. Ochterski, R. L. Martin, K. Morokuma, V. G. Zakrzewski, G. A. Voth, P. Salvador, J. J. Dannenberg, S. Dapprich, A. D. Daniels, Ö. Farkas, J. B. Foresman, J. V. Ortiz, J. Cioslowski, D. J. Fox, Gaussian, Inc., Wallingford, CT, USA, 2009

[35] a) A. D. Becke, J. Chem. Phys. 1993, 98, 5648-5652; b) C. Lee, W. Yang, R. G. Parr, Phys. Rev. B 1988, 37, 785-789; c) S. H. Vosko, L. Wilk, M. Nusair, Can. J. Phys. 1980, 58, 1200-1211; d) P. J. Stephens, F. J. Devlin, C. F. Chabalowski, M. J. Frisch, J. Chem. Phys. 1994, 98, 11623-11627; e) G. A. Petersson, A. Bennett, T. G. Tensfeldt, M. A. Al-Laham, W. A. Shirley, J. Mantzaris, J. Chem. Phys. 1988, 89, 2193-2218; f) G. A. Petersson, M. A. Al-Laham, J. Chem. Phys. 1991, 94, 6081-6090.

[36] a) http://www.tc.uni-koeln.de/PP/clickpse.en.html (accessed 9.2.2018); b) M. Dolg, H. Stoll, A. Savin, H. Preuss, Theor. Chim. Acta 1989, 75, $173-$ 194; c) M. Dolg, H. Stoll, H. Preuss, Theor. Chim. Acta 1993, 85, 441-450.

[37] G. N. Murshudov, A. A. Vagin, E. J. Dodson, Acta Crystallogr. Sect. D Biol. Crystallogr. 1997, 53, 240-255.

Manuscript received: March 9, 2018

Accepted manuscript online: March 10, 2018

Version of record online: April 16, 2018 